\title{
High-resolution elevation mapping of the McMurdo Dry Valleys, Antarctica, and surrounding regions
}

\author{
Andrew G. Fountain ${ }^{1}$, Juan C. Fernandez-Diaz ${ }^{2}$, Maciej Obryk ${ }^{1}$, Joseph Levy ${ }^{3}$, Michael Gooseff ${ }^{4}$, \\ David J. Van Horn ${ }^{5}$, Paul Morin ${ }^{6}$, and Ramesh Shrestha ${ }^{2}$ \\ ${ }^{1}$ Department of Geology Portland State University, Portland, OR 97201, USA \\ ${ }^{2}$ National Center for Airborne Laser Mapping, University of Houston, Houston, TX 77204, USA \\ ${ }^{3}$ University of Texas, Institute for Geophysics, Jackson School of Geosciences, Austin, TX 78758, USA \\ ${ }^{4}$ Institute of Arctic \& Alpine Research, University of Colorado, CO Boulder, 80309 \\ ${ }^{5}$ Department of Biology, University of New Mexico, Albuquerque, NM 87131, USA \\ ${ }^{6}$ Polar Geospatial Center, University of Minnesota, St. Paul, MN 55108, USA \\ Correspondence to: Andrew G. Fountain (andrew@pdx.edu)
}

Received: 8 December 2016 - Discussion started: 5 January 2017

Revised: 27 May 2017 - Accepted: 29 May 2017 - Published: 12 July 2017

\begin{abstract}
We present detailed surface elevation measurements for the McMurdo Dry Valleys, Antarctica derived from aerial lidar surveys flown in the austral summer of 2014-2015 as part of an effort to understand geomorphic changes over the past decade. Lidar return density varied from 2 to $>10$ returns $\mathrm{m}^{-2}$ with an average of about 5 returns $\mathrm{m}^{-2}$. Vertical and horizontal accuracies are estimated to be 7 and $3 \mathrm{~cm}$, respectively. In addition to our intended targets, other ad hoc regions were also surveyed including the Pegasus flight facility and two regions on Ross Island, McMurdo Station, Scott Base (and surroundings), and the coastal margin between Cape Royds and Cape Evans. These data are included in this report and data release. The combined data are freely available at https://doi.org/10.5069/G9D50JX3.
\end{abstract}

The McMurdo Dry Valleys (MDV) are a polar desert located along the Ross Sea coast of East Antarctica $\left(\sim 77.5^{\circ} \mathrm{S}\right.$, $\sim 162.5^{\circ} \mathrm{E}$; Fig. 1). These valleys are not covered by the East Antarctic ice sheet due to the blockage to flow by the Transantarctic Mountains and the severe rain shadow caused by these mountains (Chinn, 1981; Fountain et al., 2010). The valleys are a mosaic of gravelly sandy soil, glaciers, icecovered lakes, and ephemeral melt streams that flow from the glaciers. Permafrost is ubiquitous, with active layers up to $75 \mathrm{~cm}$ deep (Bockheim et al., 2007). This region is of interest to geologists and biologists. It is one of the few regions in Antarctica with exposed bedrock from which the tectonic history of the continent can be explored (Gleadow and Fitzgerald, 1987; Marsh, 2004). The bare landscape also provides evidence for past glaciations, a critical look into the past behavior of the Antarctic Ice Sheet (Brook et al., 1993;
Denton and Hughes, 2000; Hall et al., 2010). The cold dry environment of the MDV hosts an unusual terrestrial habitat dominated by microbial life (Adams et al., 2006; Cary et al., 2010) and serves as a useful terrestrial analogue for Martian conditions (Kounaves et al., 2010; Levy et al., 2008; Samarkin et al., 2010).

Over the last decade the topography of the coastal margins has been changing due to melting of subsurface deposits of massive ice (Bindschadler et al., 2008; Fountain et al., 2014). For example, the Garwood River in Garwood Valley has rapidly eroded through ice-cemented permafrost and buried massive ice (Levy et al., 2013) sometime after December 2000. In Taylor Valley, observations in 2014-2015 along Commonwealth Stream showed a similar erosive behavior. Other streams in Taylor Valley, including Crescent, Lost Seal, and Lawson, have exhibited recent bank undercutting (Gooseff et al., 2016). Over the 50+ years of observations these changes are the first of their kind. Also, we 


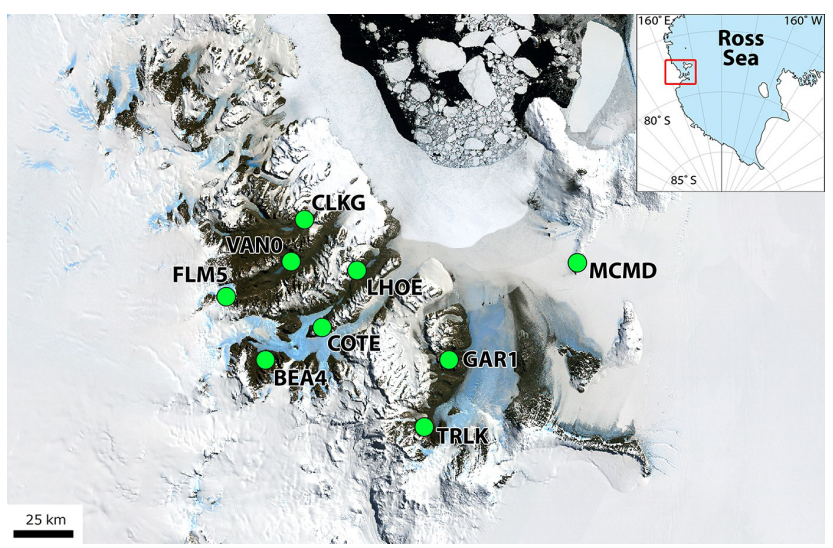

Figure 1. Landsat image mosaic of Antarctica, LIMA (Bindschadler et al., 2008), map of the central McMurdo Dry Valleys with locations of UNAVCO fixed Global Positioning System ground stations.

have observed glacier thinning where significant sediment deposits have collected on the surface (Fountain et al., 2014).

Common to all changes is the occurrence of a relatively thin veneer of sediment over massive ice. In the case of the valley floor the sediment veneer is $\sim 10^{-1} \mathrm{~m}$ in thickness, whereas on the glaciers it is patchy, with thicknesses of $\sim 10^{-3}$ to $10^{-2} \mathrm{~m}$. In addition, anecdotal observations point to large changes in other stream channels and increasing roughness and perhaps thinning of the lower elevations of some glaciers.

To assess the magnitude and spatial distribution of landscape changes, the valleys were surveyed using a highresolution airborne topographic lidar during the austral summer of 2014-2015 and the results were compared to an earlier survey flown in the summer of 2001-2002 (Csatho et al., 2005; Schenk et al., 2004). Our working hypothesis is that landscape change is limited to the coastal thaw zone where maximum summer temperatures exceed $-5^{\circ} \mathrm{C}$ (Fountain et al., 2014; Marchant and Head, 2007). Here we summarize the field campaign of 2014-2015, data processing, and the point cloud of elevation data covering about $3300 \mathrm{~km}^{2}$ of the $\mathrm{MDV}$, and $264 \mathrm{~km}^{2}$ of areas of interest nearby, all of which have been made openly available to the research community.

\section{Approach}

In early December 2014, the lidar personnel from the National Science Foundation's National Center for Airborne Laser Mapping (NCALM) and the science team from Portland State University arrived at McMurdo Station for an 8week field season. Two airborne laser scanner (ALS) instruments were used in the survey. The main instrument was the Titan multiwave (MW), a newly designed multispectral ALS based on performance specifications provided by NCALM, with an integrated digital camera manufactured for
NCALM by Teledyne Optech, Inc., Toronto, Canada. It is the first operational ALS designed to perform mapping using three different wavelengths simultaneously through the same scanning mechanism (Fernandez-Diaz et al., 2016a, b). Two wavelengths are in the near-infrared spectrum (1550 and $1064 \mathrm{~nm})$ and the third is in the visible spectrum $(532 \mathrm{~nm})$. This three-wavelength capability enables the Titan MW to map elevations of solid ground (topography) and depths below water surface (bathymetry - but not available for reasons described later) simultaneously. This three-channel spectral information can be combined into false-color laser backscatter images, which improves the ability to distinguish between types of land cover. The system is mounted under the aircraft, scanning side to side at an angle of up to $\pm 30^{\circ}$ off nadir, producing a sawtooth ground pattern. There are $1064 \mathrm{~nm}$ channel points at nadir and 1550 and $532 \mathrm{~nm}$ channel point 3.5 and $7^{\circ}$ forward of nadir, respectively. Each channel can acquire up to 300000 measurements per second. However, the nominal operation pulse repetition rate for the MDV survey was $100 \mathrm{kHz}$ per channel. For some extreme regions where the terrain relief was extremely high, the Titan MW had to be operated at lower pulse rates of 75 and $50 \mathrm{kHz}$. For each pulse the Titan only records first, second, third, and last returns. The Titan scanner was operated at an angle of $\pm 30^{\circ}$ and a frequency of $20 \mathrm{~Hz}$.

The advantage of Titan MW over traditional ALS systems for mapping regions like the MDV where areas of soil and snow overlap is the multiple channels at different wavelengths. A traditional ALS operating at $1550 \mathrm{~nm}$ obtains strong returns from the soil surfaces but may have difficulties over ice and snow, which reflect less at that wavelength. The additional 1064 and $532 \mathrm{~nm}$ channels have a better response to snow. Also, three channels collecting data simultaneously increases the data density compared to single-channel units. However, a limitation of the Titan system is the maximum range of $\sim \leq 2 \mathrm{~km}$.

The second ALS was an Optech Gemini airborne laser terrain mapper (ALTM), which served as a backup to the Titan MW. The Gemini ALTM is a single-channel system that uses $1064 \mathrm{~nm}$ laser pulses at repetition frequencies of 33 to $166 \mathrm{kHz}$ and it can scan a swath of up to $\pm 25^{\circ}$ off nadir. While the return densities obtained with the Gemini are lower than those from the Titan MW system, it has the advantage of a longer maximum range of $\sim \leq 4 \mathrm{~km}$. The Gemini was operated at pulse rate frequency between 70 and $100 \mathrm{kHz}$, its scanner ran at $\pm 25^{\circ}$ and a frequency of $35 \mathrm{~Hz}$; its beam divergence was set at 0.25 milliradians.

The DiMAC Ultralight camera, integrated into the Titan MW system, acquires digital vertical aerial photographs during the laser scanning and together they can produce digital orthophotographs. The camera uses a charged coupled device (CCD) with 60 megapixels, each with a dimension of $6 \mu \mathrm{m} \times 6 \mu \mathrm{m}$. The pixels are arranged in an array of 8984 pixels oriented perpendicular to the flight direction and 6732 pixels along the flight direction, which translates to a CCD 

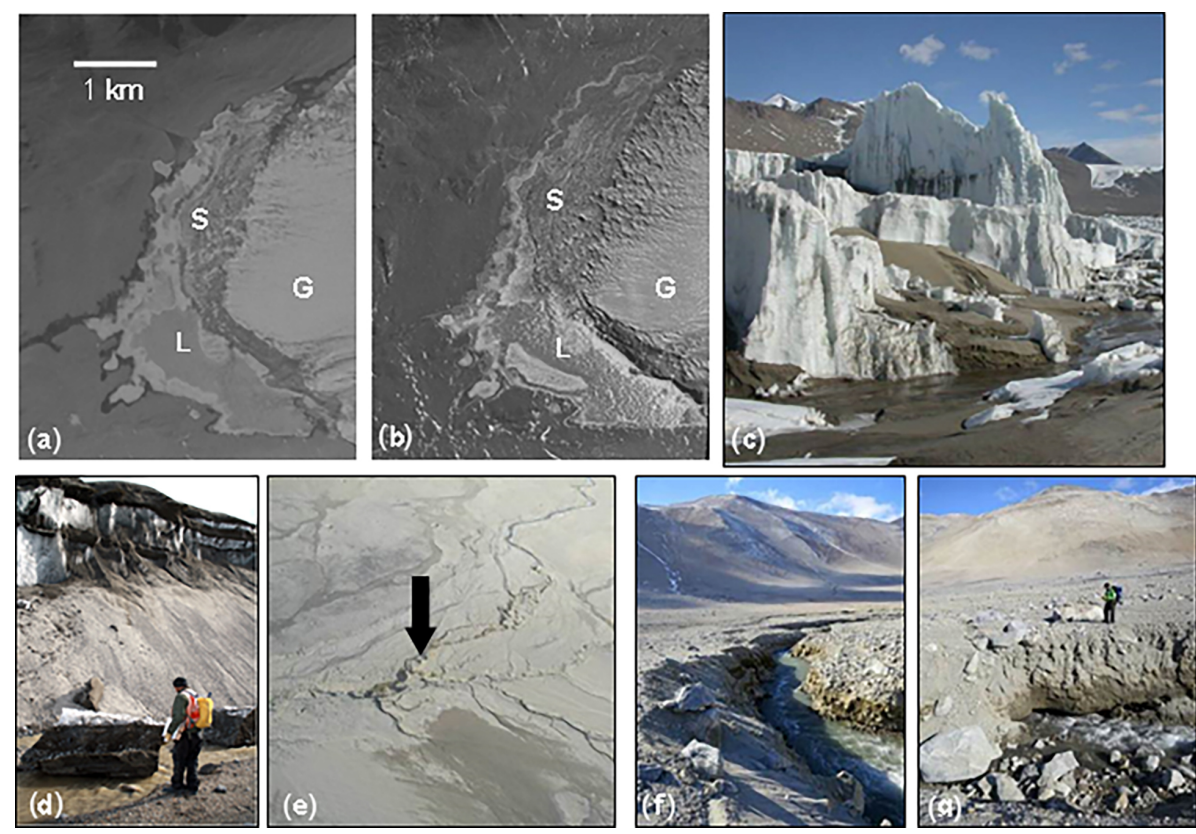

Figure 2. Examples of ice-mediated elevation changes in the McMurdo Dry Valleys. Disintegration of the lower ablation zone of the Wright Lower Glacier, Wright Valley, (a) 1980 and (b) 2008. S is the sediment-covered part of the glacier, G is the relatively clean part of the glacier, and $\mathrm{L}$ is Lake Brownworth. The dots just below the $\mathrm{S}$ in the 2008 photo are ice spires several meters tall with sediment-covered ablated ice surrounding it, depicted in (c), photo: M. Sharp. (d) Ice cliff exposed by the eroding Garwood River. (e) Aerial view of Garwood River incision and bank collapse. River flows right to left. Arrow points to where photos (f) and (g) were taken. (f) Recent incision; note color differences. (g) The river has carved a thermokarst tunnel.

physical chip size of $5.39 \mathrm{~cm} \times 4.04 \mathrm{~cm}$. The image is formed on the focal plane through a compound lens with a focal length of $70 \mathrm{~mm}$. The combination of lens and CCD array yields a total field of view (FOV) of $42.1^{\circ} \times 32.2^{\circ}$ and a ground sample distance of $0.0000825 \times$ flight height $(\sim 5 \mathrm{~cm}$ for nominal mission altitudes of $600 \mathrm{~m}$ above ground level). The position of the CCD is adjusted during flight through a piezo actuator to compensate for the motion of the aircraft during an exposure, reducing pixel smear.

To derive accurate differential kinematic trajectories for the ALS, a total of nine UNAVCO Global Positioning System (GPS) stations were used as reference, recording data at a rate of $1 \mathrm{~Hz}$ (Fig. 1). This network of GPS stations provided sufficient coverage to ensure that the aircraft was no more than $40 \mathrm{~km}$ from any station during mapping operations.

\section{Results from the field campaign}

The Titan MW ALS was mounted within a DHC-6 Twin Otter aircraft operated by Kenn Borek Air of Calgary, Canada, under contract to the National Science Foundation. The aircraft flew at a nominal speed of $65-70 \mathrm{~m} \mathrm{~s}^{-1}$ at a nominal flight height of $600 \mathrm{~m}$ above the surface (actual flight heights above terrain ranged between 400 and $2500 \mathrm{~m}$ ). The footprint of the laser beam was about $0.3 \mathrm{~m}$ for channels 1 and 2 and about $0.6 \mathrm{~m}$ for channel 3 (Fig. 3).

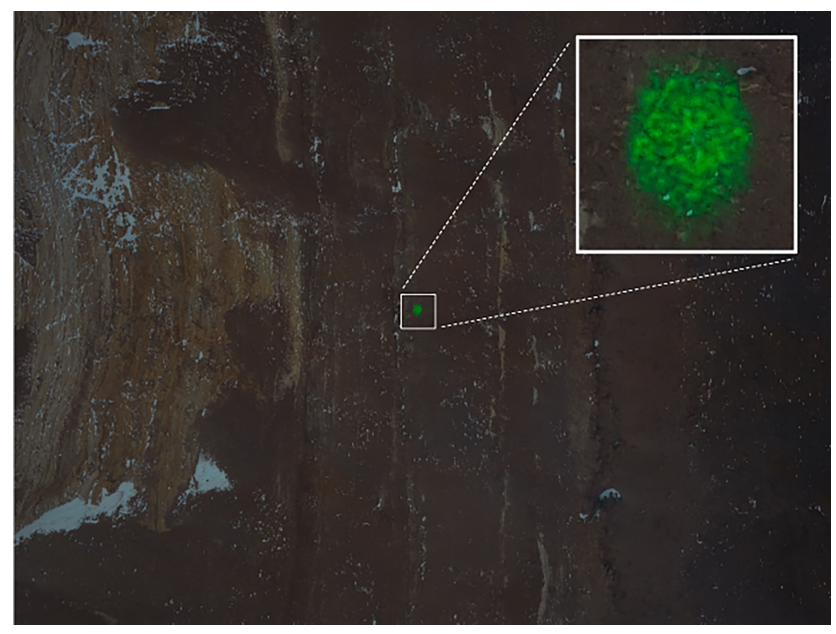

Figure 3. Image of the Titan channel $3(532 \mathrm{~nm})$ laser footprint captured by the digital camera over the floor of Wright Valley.

The aerial survey was planned to cover the entire $5000 \mathrm{~km}^{2}$ of the MDV but adverse weather conditions prevented complete coverage. Fortunately, the prioritized valley bottoms and regions previously scanned by NASA in 2001 were surveyed and none of our science objectives were compromised. Occasionally, the priority MDV targets were unavailable during flight operations and nearby ad hoc regions of oppor- 


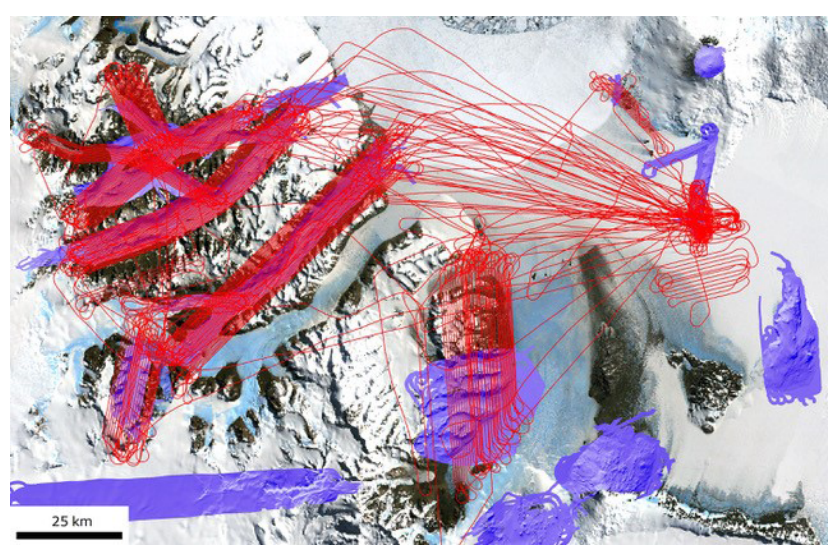

Figure 4. Flight lines for the new 2014-2015 survey (shown in red) over the extent of the 2001 survey (shown in purple) digital elevation model hillshades. Base map is the Landsat Image Mosaic of Antarctica (Bindschadler et al., 2008).

tunity were surveyed, including McMurdo Station and surroundings, Pegasus Airfield, and the coastal area between and including Cape Royds and Cape Evans. These ad hoc regions, together with the MDV, totaled about $3600 \mathrm{~km}^{2}$ from which $3564 \mathrm{~km}^{2}$ of elevation rasters of surveyed landscape was produced (Fig. 4).

Reliability of the Titan MW system was good, with only 1 day lost due to an intermittent malfunction. A total of 109 aircraft engine-on hours was used. Of these, $94.7 \mathrm{~h}$ were flying hours, which yielded a total of 50.9 laser-on hours (47.4 h with Titan MW and $3.4 \mathrm{~h}$ with Gemini). A total of 42.5 billion laser shots were fired, of which about two-thirds (28.7 billion) produced usable returns. The unusable returns were primarily due to a saturation of channel $3(532 \mathrm{~nm})$ of the Titan system. This channel is optimized for weak returns to enhance the ability to see through clear water (bathymetry). However, the detector was overwhelmed by sunlight reflections off the steep valley walls and multipath reflections produced by the highly reflective snow and ice. This caused the detector to trigger spurious returns, saturating the ability of the sensor to record actual surface returns. The remaining usable returns were equally divided between channels 1 and 2. Returns from the outer $5^{\circ}$ of either side of the swath (scan angle cutoff) were also discarded to reduce scan line artifacts.

Survey patterns were described as "mowing the lawn" as the plane flew back and forth along the longitudinal axis of each valley, with the goal of $50 \%$ overlap with the prior swath such that the edge of the newly acquired swath overlaps from the edge to the center of the adjacent previously flown swath. The separation between the flight lines was $\sim 350 \mathrm{~m}$. Due to adverse weather $50 \%$ lateral swath overlap was not always possible.

After the aircraft landed, preliminary processing was performed to examine the coverage and identify gaps to be re-

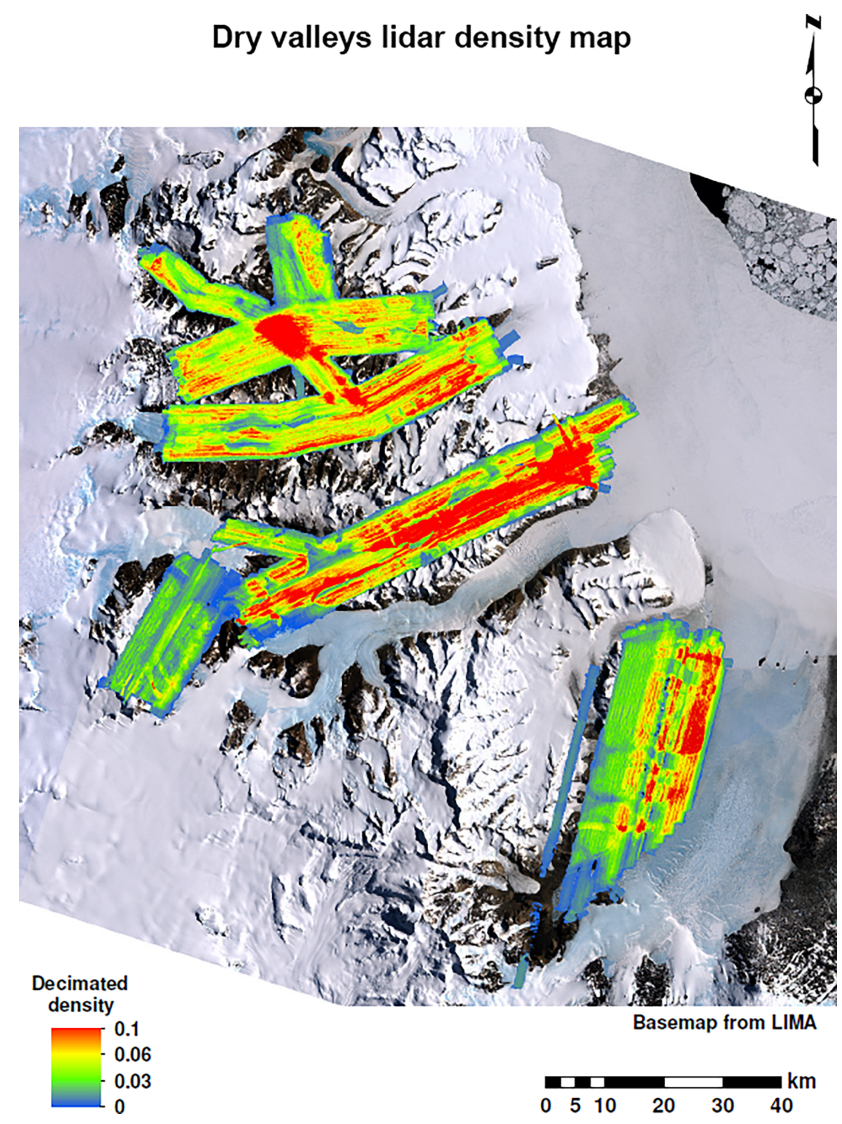

Figure 5. Return density map for the 2013-2014 lidar survey of the McMurdo Dry Valleys. The units of density are returns $\mathrm{m}^{-2} \times 10$. Base map is the Landsat Image Mosaic of Antarctica (Bindschadler et al., 2008).

flown. The time between initial and final coverage depended on weather. While the performance of Titan MW met most of its design parameters, it was not able to detect usable returns in the deeper parts of Taylor Valley because the safe flight height above local terrain exceeded the range limit of the instrument. To survey these regions, the Gemini sensor was installed towards the end of the flying season and the data gaps were closed. The resulting spatial point density of the laser returns varied due to differences in flight height, weather, and repeat coverage to close gaps (Fig. 5). Overall, the range

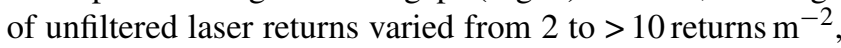
with an average of 4.7 returns $\mathrm{m}^{-2}$.

\section{Final data processing}

After returning from Antarctica the data were processed in four main steps: trajectory determination, point cloud production, point cloud processing, and elevation raster generation. The first step was to produce accurate differential trajectories for the aircraft. Initially, the three-dimensional coordinates for aircraft (sensor) position were derived from the 


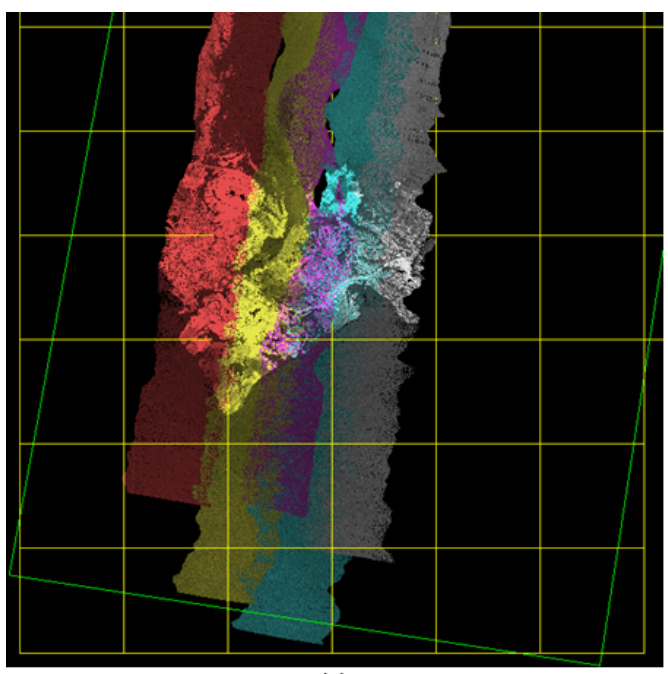

(a)

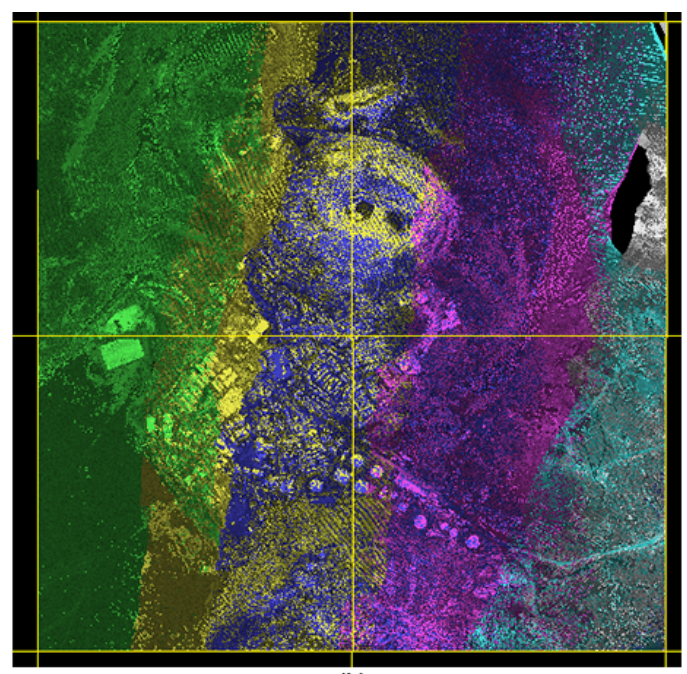

(b)

Figure 6. Lidar point cloud strips and point cloud tiles illustrating how a large coverage area is broken down into tiles. (a) Five flight strips over McMurdo Station; the strip point clouds have been rendered based on flight line and intensity. The yellow grid represents the $1 \mathrm{~km} \times 1 \mathrm{~km}$ tiles into which the returns from the different strips will be binned. (b) Point clouds for four tiles. The tiled point clouds are rendered based on flight line and intensity. The overlap between the different flight strips within each tile is evident on this rendering.

GPS stations using the KARS (Kinematic and Rapid Static) software (Mader, 1996), taking data from one GPS station at a time. For each flight its final trajectory in three dimensions was derived by blending solutions from at least three GPS stations. These data were then combined with orientation information collected from the inertial measurement unit, operating at $200 \mathrm{kHz}$. We used a Kalman filter algorithm within POSPac Mobile Mapping Suite version 7.1 (Applanix Corporation) to combine these data. The final navigation solution obtained is known as a smoothed best estimated trajectory (SBET) and resulted in a binary file containing the sensor's position and orientation.

The second processing step, point cloud production, combined the laser range data with the SBET to produce geolocated point clouds of laser returns. The point cloud production was performed with the sensor manufacturer's proprietary software LMS for the Titan MW and DASHmap for the Gemini. Before producing the point cloud for the entire project area, a small subset of the cloud was carefully examined. This geographical subset was selected before the data were collected to serve as a calibration and validation (CAL/VAL) site. The CAL/VAL site has structural and topographic features that allowed for the verification that all systematic sources of error that can affect the geometric and geolocation quality of the returns were accounted for. The calibration or boresight adjustment of an ALS ensured that returns were consistent with each other (within same and different flight lines) and reduced data artifacts. The point clouds obtained for the CAL/VAL area were visually and analytically checked and parameters were adjusted to improve the geometric quality of the returns when the point cloud was regenerated. Through this iterative process the calibra- tion was refined to obtain a final set of calibration parameters that were applied to the range data for the entire project to produce the point clouds of each flight line. Each data return was positioned in three-dimensional space by horizontal coordinates in US Geological Survey Transantarctic Mountains Projection (epsg projection 3294) and vertical coordinate in meters above the World Geodetic Survey 1984 (WGS84) ellipsoid.

In addition to the geolocation information, each return contains information regarding the strength of the backscattered energy (intensity) and the GPS time for the emission of the laser pulse. The point clouds are encoded following the American Society of Photogrammetry and Remote Sensing (ASPRS) LAS 1.2 laser return file format (.las). The point clouds produced for each flight line are referred to as strips (Fig. 6a). Because of the complexity of some strips, their size, and overlap with adjacent strips, the strips were combined and the coverage re-organized into orthogonal tiles of dimension $1 \mathrm{~km} \times 1 \mathrm{~km}$, as illustrated in Fig. 6, for simplicity in handling and further processing.

Once the point cloud was organized into tiles, the final step removed atmospheric noise, multipath returns, and outlier returns using a combination of automated algorithms and manual editing. Data from overlapping flight lines within a given tile might have been collected on different flights. Furthermore, because the vertical GPS trajectory solution may vary within a few decimeters, it was necessary to adjust the elevation of each flight strip to remove any possible bias. Elevation adjustments were performed with Terrasolid TerraMatch software. For each tile TerraMatch compared the elevations of the different flight lines within common coverage areas and computed vertical adjustment values for each flight 


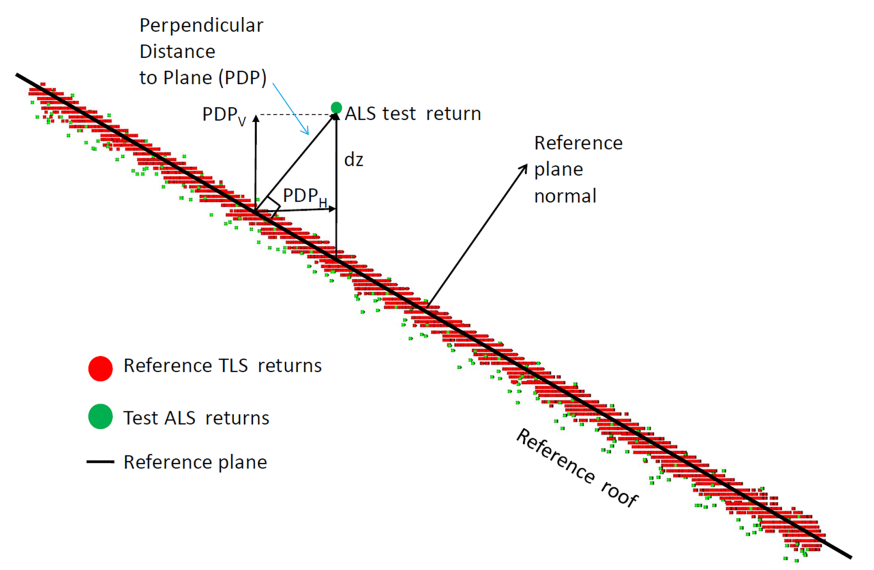

Figure 7. Illustration of assessing uncertainty for airborne lidar survey (ALS) compared to terrestrial lidar survey (TLS) of an inclined roof.

line. In addition to ensuring consistency between elevations of different flight lines, this process can be tied to control points with well-known elevations such that the adjusted elevations are also consistent with a given vertical datum. After adjusting for these vertical offsets, the final point cloud tiles were produced. Of the 28.7 billion adequate returns from the MDV, about $50 \%$ were discarded due to the $\pm 5^{\circ}$ swath edge cutoff and to noise removal, resulting in a total of 14.1 billion returns in the final point clouds.

The accuracy of the geolocation of the laser returns was verified against terrestrial laser scanning (TLS) data of buildings and structures from McMurdo Station, which were collected by Merrick and Company. Planar building roofs were selected as reference. A plane was fitted to the TLS data of a roof using the linear least squares method, and the difference in elevation $(\mathrm{dz})$ and perpendicular distance to plane were computed for respective airborne returns for the same planar roof surfaces (Fig. 7). The advantage of this method over the traditional methods of collecting kinematic GPS measurements over flat uniform surfaces such as roads and runways (Heidemann, 2014) is that it permits decomposition of the accuracy in both horizontal and vertical components. A total of 35 planes were employed for the accuracy assessment, consisting of almost 560000 TLS measurements and a total of 5008 airborne lidar returns.

The RMSE for the distance-to-plane measurement was $7.6 \mathrm{~cm}$, with a vertical and horizontal component RMSE of 6.9 and $3.2 \mathrm{~cm}$, respectively. It is important to make two critical observations regarding these values. First, this method might provide higher RMSE values than the traditional method because the geolocation of the TLS dataset has positional uncertainties higher than a vehicle kinematic survey, which is generally used as a reference dataset for the traditional method. Second, the horizontal uncertainty is probably an underestimate, and while it represents an average value under constrained conditions (low airplane dynamics,

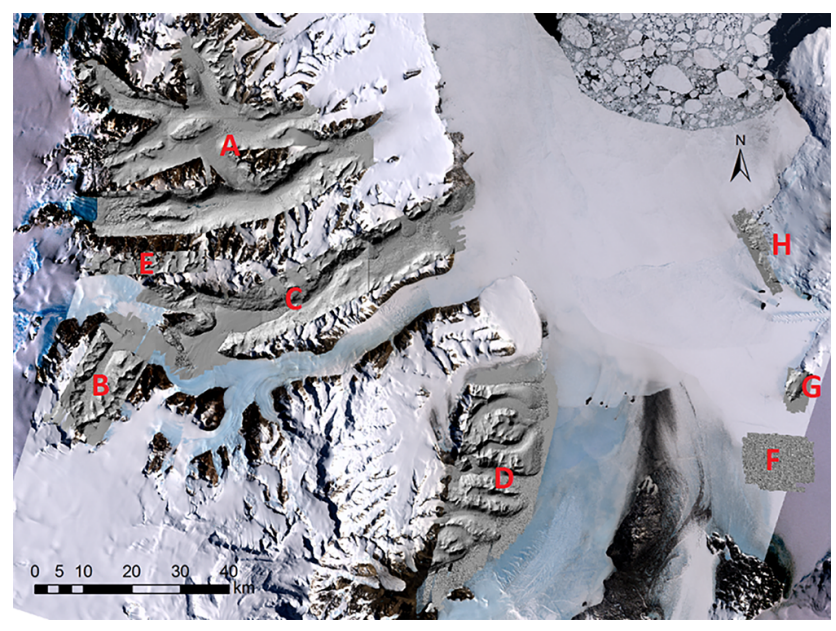

Figure 8. Shaded relief maps of the McMurdo Dry Valleys based on aerial lidar surveys conducted from December to January 20142015. A is the northern valleys of Victoria, Barwick, McKelvey, and Wright with adjacent valleys; B is Beacon Valley and surroundings; $C$ is Taylor Valley and surroundings; and D is the southern Dry Valleys of Garwood, Miers, Marshall, and adjacent valleys. E is a section of the Asgard ranges, F is Pegasus Airfield, G is the McMurdo Station area, and $\mathrm{H}$ is Capes Royds and Evans. Base map is the Landsat Image Mosaic of Antarctica (Bindschadler et al., 2008).

$600 \mathrm{~m}$ range), the horizontal uncertainty can be as high as $20-30 \mathrm{~cm}$ under more unfavorable flight conditions.

With the finalized point clouds, irregularly spaced data were interpolated, using Kriging methods, to a regularly spaced grid at $1 \mathrm{~m}$ intervals, forming digital elevation models (DEMs). The algorithm was applied to each tile and included returns $10 \mathrm{~m}$ into the neighboring tiles to avoid tile boundary artifact. The tiles were mosaicked into large coverage rasters $\left(\sim 400 \mathrm{~km}^{2}\right)$ and converted into ArcGIS elevation rasters. The gridding, mosaicking, and conversion of the DEMs was performed using Surfer software (Golden Software, Golden, CO). The ArcGIS elevation rasters were used to produce shaded relief images of the valley images with standard illumination parameters: Azimuth $315^{\circ}$, elevation $45^{\circ}$, and $Z$ factor 1 (Fig. 8).

\section{Data products}

Three types of data products derived from the lidar survey are available. Spatial coverage for these products includes five regions within the McMurdo Dry Valleys (Fig. 9): (1) Taylor Valley, which also includes Pearse Valley; (2) the northern valleys, which include Wright, McKelvey, Balham, Barwick, and the Victoria valleys; (3) the southern valleys, which include Garwood, Marshall, and Miers valleys and surrounding areas; (4) Beacon Valley; and (5) a section of the Asgard Range. The spatial coverage also includes three ad hoc regions: (1) the Pegasus aviation facility, (2) McMurdo Station and surroundings, and (3) the coastal margin from Cape 
Table 1. Summary of available lidar data products. Returns are the lidar returns from the Earth's surface; no. of LAS tiles is the number of point cloud tiles for each section; LAS Gb is the data storage size in gigabytes for the point cloud data; no. of sections is the number of individual sections that constitute the entire elevation raster for each region; DEM Gb is the data storage size in gigabytes of the digital elevation model that covers that region; SRM Gb is the data storage size in gigabytes of the shaded relief maps.

\begin{tabular}{|c|c|c|c|c|c|c|c|}
\hline \multirow[t]{2}{*}{ Region } & \multirow[t]{2}{*}{ Coverage area $\mathrm{km}^{2}$} & \multicolumn{3}{|c|}{ Point cloud products } & \multicolumn{3}{|c|}{ Elevation rasters } \\
\hline & & Returns $\times 10^{6}$ & No. of LAS tiles & LAS Gb & No. of sections & DEM Gb & $\mathrm{SRM} \mathrm{Gb}$ \\
\hline Taylor & 852.8 & 4112.5 & 944 & 107.0 & 3 & 6.8 & 1.0 \\
\hline Northern & 1289.8 & 5417.2 & 1447 & 141.0 & 3 & 10.1 & 1.6 \\
\hline Southern & 755.1 & 2800.7 & 827 & 73.0 & 2 & 5.5 & 0.9 \\
\hline Beacon Valley & 316.1 & 651.4 & 376 & 16.9 & 1 & 3.1 & 0.4 \\
\hline Asgard Range & 94.8 & 129.5 & 136 & 3.4 & 1 & 0.7 & 0.1 \\
\hline Pegasus & 157.8 & 504.3 & 181 & 13.1 & 1 & 0.9 & 0.1 \\
\hline McMurdo & 42.3 & 257.9 & 59 & 6.7 & 1 & 0.3 & 0.1 \\
\hline Royds \& Evans & 63.4 & 253.3 & 92 & 6.6 & 1 & 0.9 & 0.1 \\
\hline
\end{tabular}

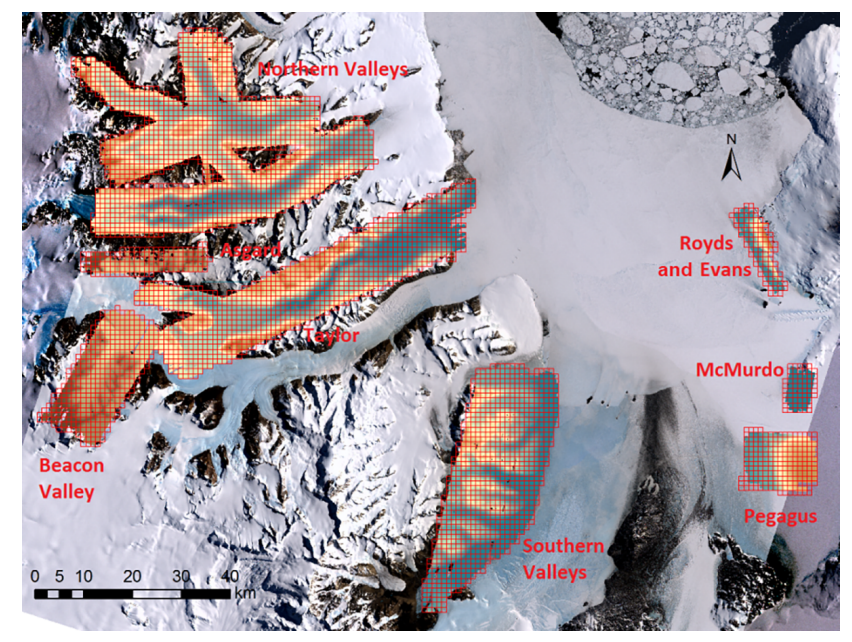

Figure 9. Map showing the location and extent of the available lidar data products. Base map is the Landsat Image Mosaic of Antarctica (Bindschadler et al., 2008).

Royds to Cape Evans. The lidar data products include clean point clouds in $1 \mathrm{~km} \times 1 \mathrm{~km}$ tiles in the ASPRS .las format, DEMs in the Esri ArcGIS .flt format, and shaded relief maps in the Esri ArcGIS .adf format. The ArcGIS rasters have a horizontal resolution of $1 \mathrm{~m}$. Specifics related to the extent and file size of these data products for each of the survey areas are summarized in Table 1.

\section{Data availability}

The data products in this report can be obtained from two different data facilities funded by the National Science Foundation: Open Topography, www.opentopography. org (the web page hosting the data can be found at https://doi.org/10.5069/G9D50JX3, Fountain, 2016) and the Polar Geospatial Center at www.pgc.umn.edu.
It is important to note that the data formats for each data product listed in this report correspond to the formats in which the data products were delivered to OpenTopography and the Polar Geospatial Center. However, each of these data repositories may provide the data in different formats depending on their own protocols, and in future the format may change to follow the evolution of data formats.

\section{Summary}

We have compiled a high-resolution elevation dataset for $3564 \mathrm{~km}^{2}$ of the McMurdo Dry Valleys, Antarctica, focused largely (but not exclusively) on the valley bottoms. These new data, with a return density averaging 5 returns $\mathrm{m}^{-2}$, improve the raster DEM quality compared to the lidar survey flown in 2002 (Shenk et al., 2004) by a factor of 4, from 2 to $1 \mathrm{~m}^{2}$. We also include an estimate of uncertainties based on detailed terrestrial lidar surveys of building roofs at McMurdo Station collected independently from our investigation. This approach differs from the traditional method of a vehicle-mounted GPS unit driven over a flat surface of a road by using inclined surfaces yielding both vertical and horizontal uncertainties. Comparing the elevations of 35 inclined building roofs, our RMSE uncertainty is $\pm 0.07 \mathrm{~m}$ in the vertical and $\pm 0.03 \mathrm{~m}$ in the horizontal. However, we recognize that the horizontal uncertainty may be as much as 1 order of magnitude higher due to poor flight conditions. In addition to the primary mission of the project, we also surveyed nearby regions, including the Pegasus aviation facility on the McMurdo Ice Shelf, and two localities on Ross Island, the region covering McMurdo Station and Scott Base, and the coastal margin from Cape Royds to Cape Evans. Data products include point clouds provided in $1 \mathrm{~km} \times 1 \mathrm{~km}$ tiles, $1 \mathrm{~m}$ resolution digital elevation models, and shaded relief maps. 
Author contributions. All authors contributed to the drafting and editing of the paper. Andrew Fountain was the principle investigator of the project, writing the proposal and working in the field with the NCALM group flying the lidar. He helped to examine the final data quality and led the writing of this report. Juan Fernandez-Diaz was lead for the aerial lidar survey, coordinating the flights, instrument operations, and data production and performing final data quality assessments and verifications. He also wrote major sections of this report. Maciej Obryk led the field campaign to deploy the GPS receivers for the aircraft and worked on the data quality issues. Joseph Levy was a co-principle investigator of the project and helped with data quality issues. Michael Gooseff and David Van Horn were coprinciple investigators of the project. Paul Morin helped design the project and provided logistical and technical support for the crew in the field (deploy GPS receivers) and during data processing. Ramesh Shrestha helped organize the lidar and field strategy and coordinated among the principle investigators and funding agency.

Competing interests. The authors declare that they have no conflict of interest.

Acknowledgements. The GPS units and data were provided by the polar operations group of UNAVCO and we particularly acknowledge Joe Pettit for making this operation easy and efficient. Members of the Polar Geospatial Center aided us in the deployment and collection of the GPS units. The pilots and support staff of Kenn Borek Air Ltd. were great to work with, showed much patience in flying endless flight lines, and kept to the desired trajectory despite unexpected turbulence. The NCALM personnel responsible for the collection and processing of lidar and imagery data for this project include Abhinav Singhania, Darren Hauser, and Michael Sartori. Matt Bethel, director of operations and technology, and Erick Mena, senior laser scanning technician of Merrick \& Company, provided terrestrial laser scanning data of McMurdo Station that were used for accuracy assessment of the airborne lidar data. We also thank all the people that make working and living at McMurdo Station, Antarctica, possible. This work was supported by NSF Antarctic Integrated Systems Science award ANT-1246342 to AGF.

Edited by: David Carlson

Reviewed by: James Dickson and one anonymous referee

\section{References}

Adams, B. J., Bardgett, R. D., Ayres, E., Wall, D. H., Aislabie, J., Bamforth, S., Bargagli, R., Cary, C., Cavacini, P., Connell, L., Convey, P., Fell, J. W., Frati, F., Hogg, I. D., Newsham, K. K., O’Donnell, A., Russell, N., Seppelt, R. D., and Stevens, M. I.: Diversity and distribution of Victoria Land biota, Soil Biol. Biochem., 38, 3003-3018, https://doi.org/10.1016/j.soilbio.2006.04.030, 2006.

Bindschadler, R. A., Vornberger, P., Fleming, A., Fox, A. D., Mullins, J., Binnie, D., Paulsen, S., Granneman, B., and Gorodetzky, D.: The Landsat image mosaic of Antarctica, Remote Sens. Environ., 112, 4214-4226, https://doi.org/10.1016/j.rse.2008.07.006, 2008.

Bockheim, J. G., Campbell, I. B., and McLeod, M.: Permafrost distribution and active-layer depths in the McMurdo Dry Valleys, Antarctica, Permafrost. Periglac., 18, 217-227, https://doi.org/10.1002/ppp.588, 2007.

Brook, E. J., Kurz, M. D., Ackert Jr., R. P., Denton, G. H., Brown, E. T., Raisbeck, G. M., and Yiou, F.: Chronology of Taylor Glacier advances in Arena Valley, Antarctica, using in situ cosmogenic 3He and 10Be., Quaternary Res., 39, 11-23, 1993.

Cary, S. C., McDonald, I. R., Barrett, J. E., and Cowan, D. A.: On the rocks: the microbiology of Antarctic Dry Valley soils, Nat. Rev. Microbiol., 8, 129-138, https://doi.org/10.1038/nrmicro2281, 2010.

Chinn, T. J. H.: Hydrology and climate in the Ross Sea area, J. R. Soc. N. Z., 11, 373-386, https://doi.org/10.1080/03036758.1981.10423328, 1981.

Csatho, B., Schenk, T., Krabill, W., Wilson, T., Lyons, G. M., Hallam, C., Manizade, S., and Paulsen, T.: Airborne laser scanning for high-resolution mapping of Antarctica, Eos, 86, 237-238, 2005.

Denton, G. H. and Hughes, T. J.: Reconstruction of the Ross ice drainage system, Antarctica, at the last glacial maximum, Geogr. Ann. Ser. Phys. Geogr., 82, 143-166, 2000.

Fernandez-Diaz, J., Carter, W., Glennie, C., Shrestha, R., Pan, Z., Ekhtari, N., Singhania, A., Hauser, D., and Sartori, M.: Capability Assessment and Performance Metrics for the Titan Multispectral Mapping Lidar, Remote Sens., 8, 936, https://doi.org/10.3390/rs8110936, 2016a.

Fernandez-Diaz, J. C., Carter, W. E., Shrestha, R., and Glennie, C. L.: Multicolor terrain mapping documents critical environments, EOS Trans. Am. Geophys. Union, 97, 10-15, https://doi.org/10.1029/2016EO053489, 2016b.

Fountain, A. G., Nylen, T. H., Monaghan, A., Basagic, H. J., and Bromwich, D.: Snow in the McMurdo Dry Valleys, Antarctica, Int. J. Climatol., 30, 633-642, https://doi.org/10.1002/joc.1933, 2010.

Fountain, A. G., Levy, J. S., Gooseff, M. N., and Van Horn, D.: The McMurdo Dry Valleys: A landscape on the threshold of change, Geomorphology, 225, 25-35, https://doi.org/10.1016/j.geomorph.2014.03.044, 2014.

Fountain, A. G., Fernandez-Diaz, J. C., Obryk, M., Levy, J., Gooseff, M., Van Horn, D. J., Morin, P., and Shrestha, R.: 2014 2015 lidar survey of the McMurdo Dry Valleys, Antarctica, https://doi.org/10.5069/G9D50JX3, 2016.

Gleadow, A. J. W. and Fitzgerald, P. G.: Uplift history and structure of the Transantarctic Mountains: new evidence from fission traack dating of basement apatites in the Dry Valleys area, southern Victoria Land, Earth Planet. Sc. Lett., 82, 1-14, 1987.

Gooseff, M. N., Van Horn, D., Sudman, Z., McKnight, D. M., Welch, K. A., and Lyons, W. B.: Stream biogeochemical and suspended sediment responses to permafrost degradation in stream banks in Taylor Valley, Antarctica, Biogeosciences, 13, 17231732, https://doi.org/10.5194/bg-13-1723-2016, 2016.

Hall, B. L., Denton, G. H., Fountain, A. G., Hendy, C. H., and Henderson, G. M.: Antarctic lakes suggest millennial reorganizations of Southern Hemisphere atmospheric and oceanic circulation, P. Natl. Acad. Sci. USA, 107, 21355-21359, 2010. 
Heidemann, H. K.: Lidar base specification (ver. 1.2, November 2014), 2014.

Kounaves, S. P., Stroble, S. T., Anderson, R. M., Moore, Q., Catling, D. C., Douglas, S., McKay, C. P., Ming, D. W., Smith, P. H., Tamppari, L. K., and Zent, A. P.: Discovery of Natural Perchlorate in the Antarctic Dry Valleys and Its Global Implications, Environ. Sci. Technol., 44, 2360-2364, https://doi.org/10.1021/es9033606, 2010.

Levy, J. S., Head, J. W., Marchant, D. R. and Kowalewski, D. E.: Identification of sublimation-type thermal contraction crack polygons at the proposed NASA Phoenix landing site: Implications for substrate properties and climate-driven morphological evolution, Geophys. Res. Lett., 35, L04202, https://doi.org/10.1029/2007GL032813, 2008.

Levy, J. S., Fountain, A. G., Dickson, J. L., Head, J. W., Okal, M., Marchant, D. R., and Watters, J.: Accelerated thermokarst formation in the McMurdo Dry Valleys, Antarctica, Sci. Rep., 3, 2, https://doi.org/10.1038/srep02269, 2013.

Mader, G. L.: Kinematic and rapid static (KARS) GPS positioning: Techniques and recent experiences, in GPS trends in precise terrestrial, airborne, and spaceborne applications, 170-174, Springer, Berlin, 1996.
Marchant, D. R. and Head, J. W.: Antarctic dry valleys: Microclimate zonation, variable geomorphic processes, and implications for assessing climate change on Mars, Icarus, 192, 187222, https://doi.org/10.1016/j.icarus.2007.06.018, 2007.

Marsh, B.: A magmatic mush column rosetta stone: the McMurdo Dry Valleys of Antarctica, Eos Trans. Am. Geophys. Union, 85, 497-502, 2004.

Samarkin, V. A., Madigan, M. T., Bowles, M. W., Casciotti, K. L., Priscu, J. C., McKay, C. P., and Joye, S. B.: Abiotic nitrous oxide emission from the hypersaline Don Juan Pond in Antarctica, Nat. Geosci., 3, 341-344, https://doi.org/10.1038/ngeo847, 2010.

Schenk, T., Csathó, B., Ahn, Y., Yoon, T., Shin, S. W., and Huh, K. I.: DEM generation from the Antarctic LiDAR data: Site report, US Geol. Surv., available at: http://www.nsm.buffalo.edu/Research/rsl/research/DEM/ presentations_papers/dryvalleys_atm_sitereport_v5_04sep.pdf (last access: 1 July 2014), 2004. 